\title{
POHJAMAAN HUOKOISUUSSUHTEISTA SUOMEN MAALAJEISSA
}

\author{
Reijo Heinonen \\ Helsingin Yliopiston maanviljelyskemian laitos \\ Saapunut 22. 8. 1956
}

Tämän tutkimuksen tarkoituksena on antaa yleiskuva erilaisten viljeltyjen kivennäismaiden "ylemmän kuivakuorikerroksen» huokoisuussuhteista, lähinnä kenttäkapasiteetista ja ilmatilasta. Kenttäkapasiteetilla ymmärretään sitä v e s ip i t o i s u u t t a, mikä perusteellisesti kostuneessa maassa on senjälkeen, kun liika vesi on saanut valua pois niin kauan, että valumisen nopeus on molennaisesti hidastunut», ts. on saavutettu tietty tasapaino. Toisessa merkityksessä se tarkoittaa myös maan ol otil a a: "maa on kenttäkapasiteetissa». Käsitettä on lähemmin selostettu toisaalla $(3)$.

\section{Tutkimusmenetelmät}

Nähtävästi paras tapa selvittää pohjamaan kenttäkapasiteetti Suomen olosuhteissa on seurata maan kosteustilan muutoksia muutamina viikkoina kevätkesällä, kun pohjavesi on laskenut niin paljon tutkittavan tason alapuolelle, ettei se vaikuta tuloksiin. Savimaissa riittänee $20-30 \mathrm{~cm}$ :kin (2), mutta hietamaissa pohjaveden vaikutus ulottunee $50-100 \mathrm{~cm}$ pohjaveden pinnan yläpuolelle. Kun kylmän maan kenttäkapasiteetti on aina suurempi kuin lämpimän, on viljelyn kannalta oikean arvon saamiseksi lisäksi odotettava, kunnes maa on lämminnyt niin paljon, että kasvien kasvu ja tehokas vedenkäyttö on päässyt käyntiin. Tutkimuspaikalta on poistettava kasvipeite, sillä muuten ei vesipitoisuuden jatkuvasti vähetessä voida erottaa valumista kasvien vedenotosta.

Tällaisia 2-3 näytteenottoa käsittäviä havaintosarjoja suoritettiin vuosina 1951-52 kaikkiaan 22 koealalla. Lisäksi otettiin näiden havaintojen täydentämiseksi kuudesta koealasta näytteet vain yhden kerran, valiten sellaisen ajankohdan ja koepaikan, että maan voitiin olettaa olevan kenttäkapasiteetissa. Kullakin havaintokerralla otettiin $1 \mathrm{~m}^{2}: \mathrm{n}$ koealasta neljä rinnakkaisnäytettä pohjamaan kerroksesta $30-90 \mathrm{~cm}$. Ensin kaivettiin lapiolla $30 \mathrm{~cm}: \mathrm{n}$ syvyinen kuoppa ja kuopan pohjaan hakattiin sitten erikoisrakenteinen näytteenottoputki (kuva 1), jolla voi ottaa puhtaita ja ehjiä $60 \mathrm{~cm}: n$ pituisia profiilipötkyjä.

Aluksi käytimme Anderssonin (1) piirustusten mukaista, mutta läpimitaltaan suurempaa näytteenottoputkea. Johtunee putken suuremmasta läpimitasta $(40 \mathrm{~mm})$, että profiilin alapää melkein poikkeuksetta rikkoutui, kun putkea nostettiin maasta. 


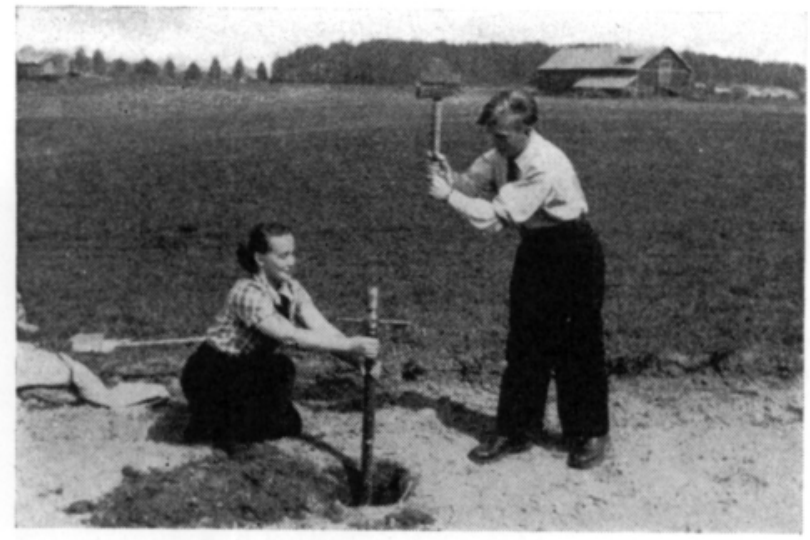

Kuva 1 - Photo 1.

Kuva $2-$ Photo 2.
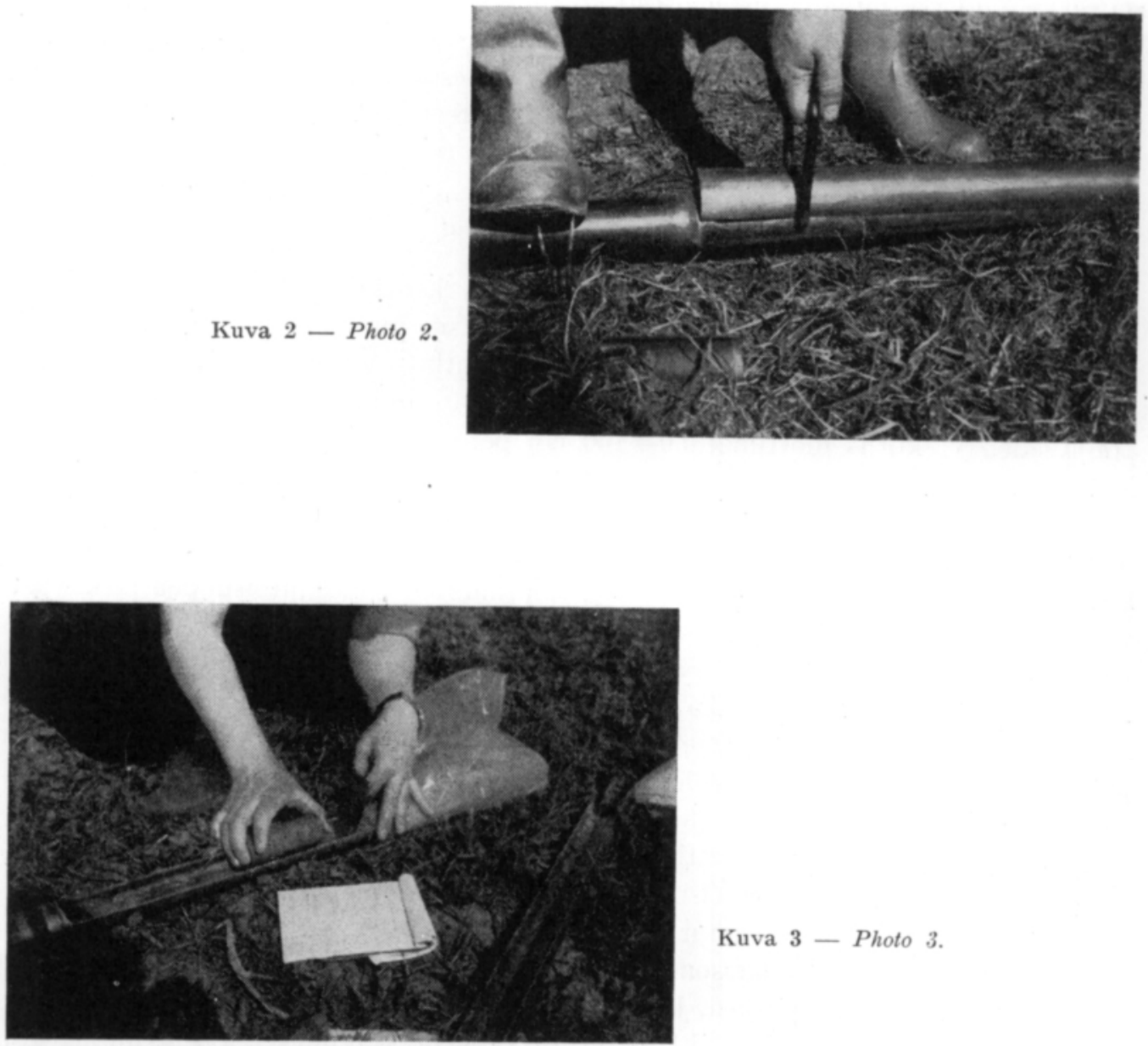

Kuva 3 - Photo 3. 
Sen vuoksi konstruoitiin aukon suojaksi irroitettavan joustava teräskansi, joka painetaan putken päälle ao. tukirenkaiden väliin ja irroitetaan tukevalla koukulla (kuva 2).

Putkessa lepäävä luonnollisen rakenteensa ja tilavuutensa säilyttänyt profiilipötky paloiteltiin pyöreäkärkisellä veitsellä $10 \mathrm{~cm}: n$ paloihin, jotka nostettiin putkesta erikoismallisella kauhalla ehjinä pois ja suljettiin muovipusseihin siihen saakka, että ne voitiin punnita (kuva 3).

Näytteenotto tuotti vaikeuksia vain hiekkamaissa, joissa näytepötky ei tahdo pysyä ehjänä, ja eräissä hyvin kosteissa savimaissa, joissa näyte pyrkii nostettaessa liukumaan ulos putkesta. Usein oli tyydyttävä nostamaan kerrallaan vain $30-40$ $\mathrm{cm}: n$ mittainen pötky ja syvemmällä esiintyvästä saippuamaisesta savesta on vaikea saada putkeen lainkaan näytettä, sillä alapäähän muodostuva tyhjiö imee nostettaessa pötkyn pois putkesta.

Kentällä punnitut näytteet saivat kuivua ilmakuiviksi, minkä jälkeen ne punnittiin uudelleen. Senjälkeen kutakin $10 \mathrm{~cm}$ :n kerrosta edustavat neljä rinnakkaisnäytettä yhdistettiin ja jauhettiin. Yhteisnäytteestä määritettiin kosteus kuivaamalla $105^{\circ} \mathrm{C}$ :ssa ja ominaispaino alkoholipikamenetelmällä (ks. 3). Lisäksi määritettiin kerrosten $40-50 \mathrm{~cm}$ ja $70-80 \mathrm{~cm}$ raekoostumus pipettimenetelmäilä. Em. määritykset suoritettiin vain yhden havaintokerran näytteistä ja muissa käytettiin samoja arvoja. Tuloksista laskettiin maan kokonaishuokostila, ilma- ja vesitila sekä tilavuuspaino.

\section{Tutkimusaineisto}

Piirroksissa $1-28$ on esitetty koealojen sijainti, huokostilasuhteet, maalaji ja havaintojen päiväys. Maiden raekoostumus on esitetty summakäyrinä piirroksissa 29-31. Maalajien nimityksissä on noudatettu uutta täsmennettyä terminologiaa (ks. 6). Kentällä tehtyjen muistiinpanojen ja suoritettujen tutkimusten perusteella voidaan piirrosten täydennykseksi esittää eri koealoista seuraavat huomautukset.

N:o 1. Tikkurila. Melko tasarakeinen hieno hiekka loivassa alarinteessä puutarhassa koelaitoksen laboratoriorakennuksen pohjoispuolella. Tummanruskea B-taso (humuspodsoli) ulottuu $80 \mathrm{~cm}: \mathrm{n}$ syvyyteen saakka ja ilmeisesti tästä syystä kenttäkapasiteetti on korkeampi kuin mitä raesuuruus sinänsä edellyttäisi.

N:o 2. Karjaa. Perusteellisesti lajittunut poutiva hiekkaharjanne kauppalan pohjoispuolella. Rautapodsolin B-taso $30-50 \mathrm{~cm}$.

N:o 3. Koeala 1:n lähellä. Maa on erilaisten tekstuuri- ja maannostasojen takia jonkinverran heterogeenistä ja topografiasta johtuen pohjavesi pysyy keväälä melko kauan korkealla. Tutkimuksessa ei tavoitettu selväpiirteistä kenttäkapasiteettitilaa.

N:o 4. Sammatti. Tyypillinen puhtaaksilajittunut punertava karkea hieta ylärinteessä. Puutarha. Ei selvãä B-tason alarajaa.

N:o 5. Vihti. Peltomaa, topografia ja maaperä edellistä läheisesti muistuttava. Maa on kuitenkin selvästi löyhempää kuin edellisissä koealoissa, mikä ilmenee suurempana huokostilana.

N:o 6. Tikkurila. Tasainen peltomaa. Jokseenkin tasarakeinen punertava karkeahko hieta.

N:o 7. Helsinki. Pieni kumpare pellon reunassa lähellä koealaa 19. Löyhä văhăkivinen hietamoreeni tiiviin hiuekerrostuman päällä. 

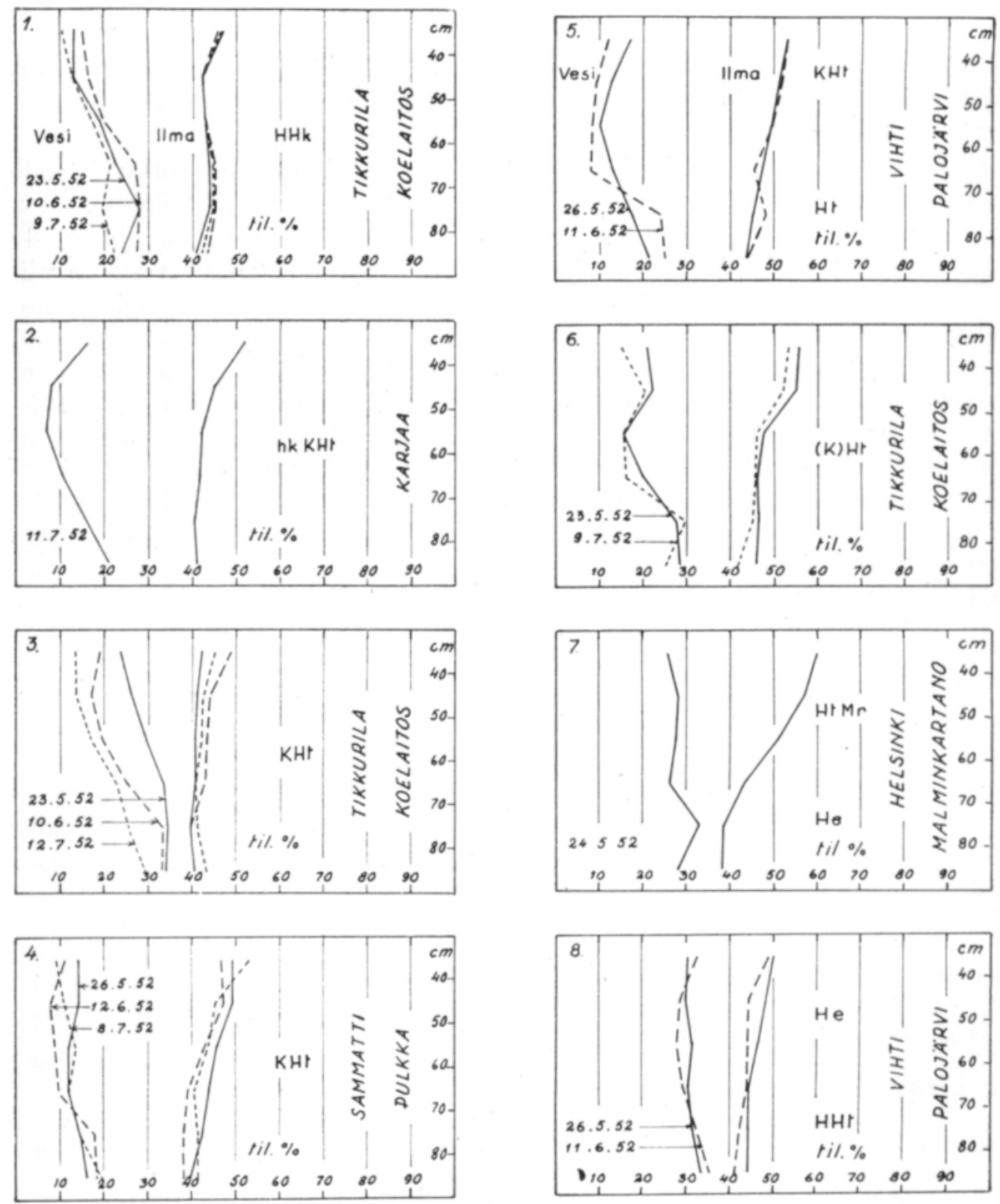

Piirrokset $1-8-$ Fig. $1-8$. 

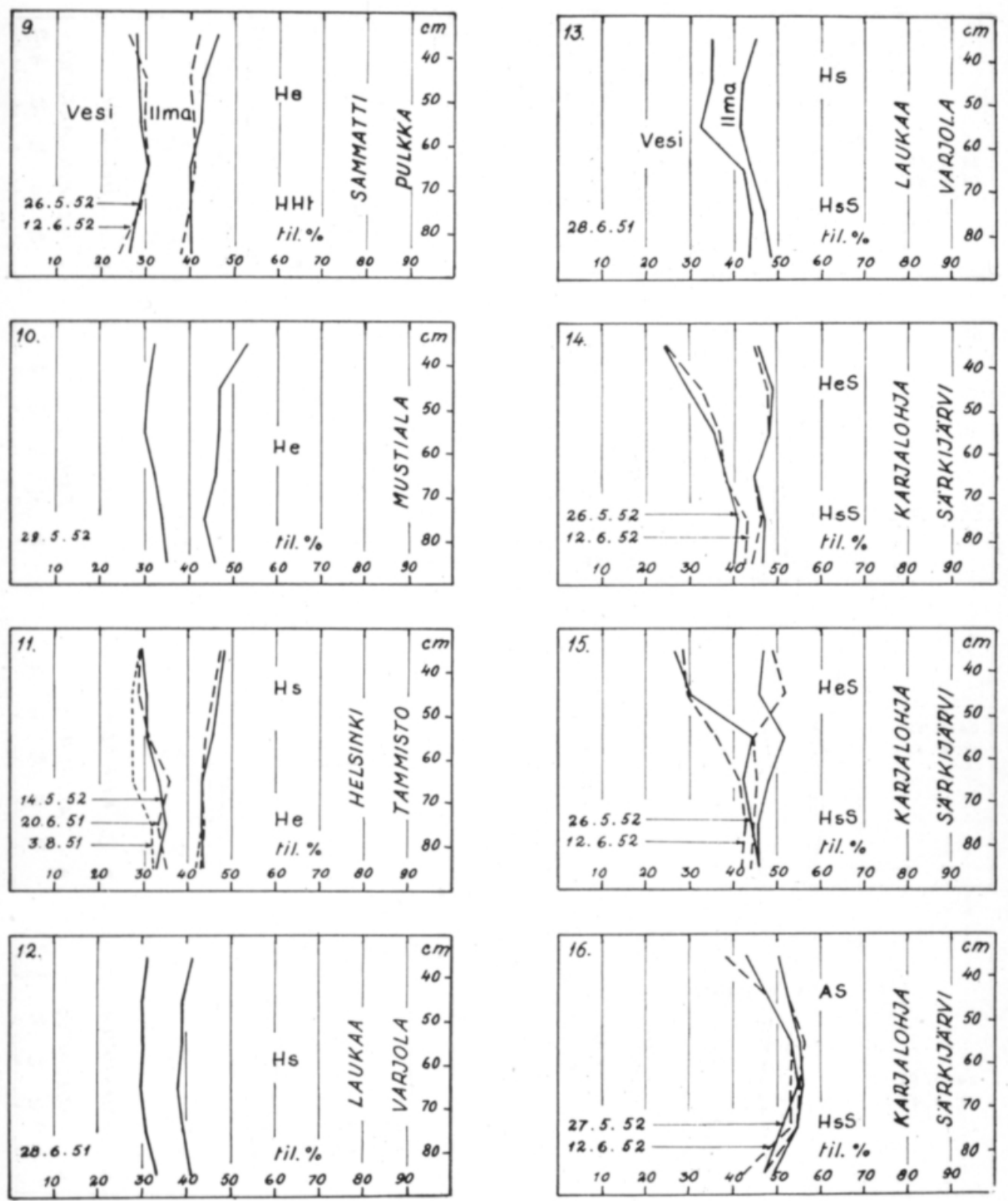

Piirrokset 9-16- Fig. 9-16. 

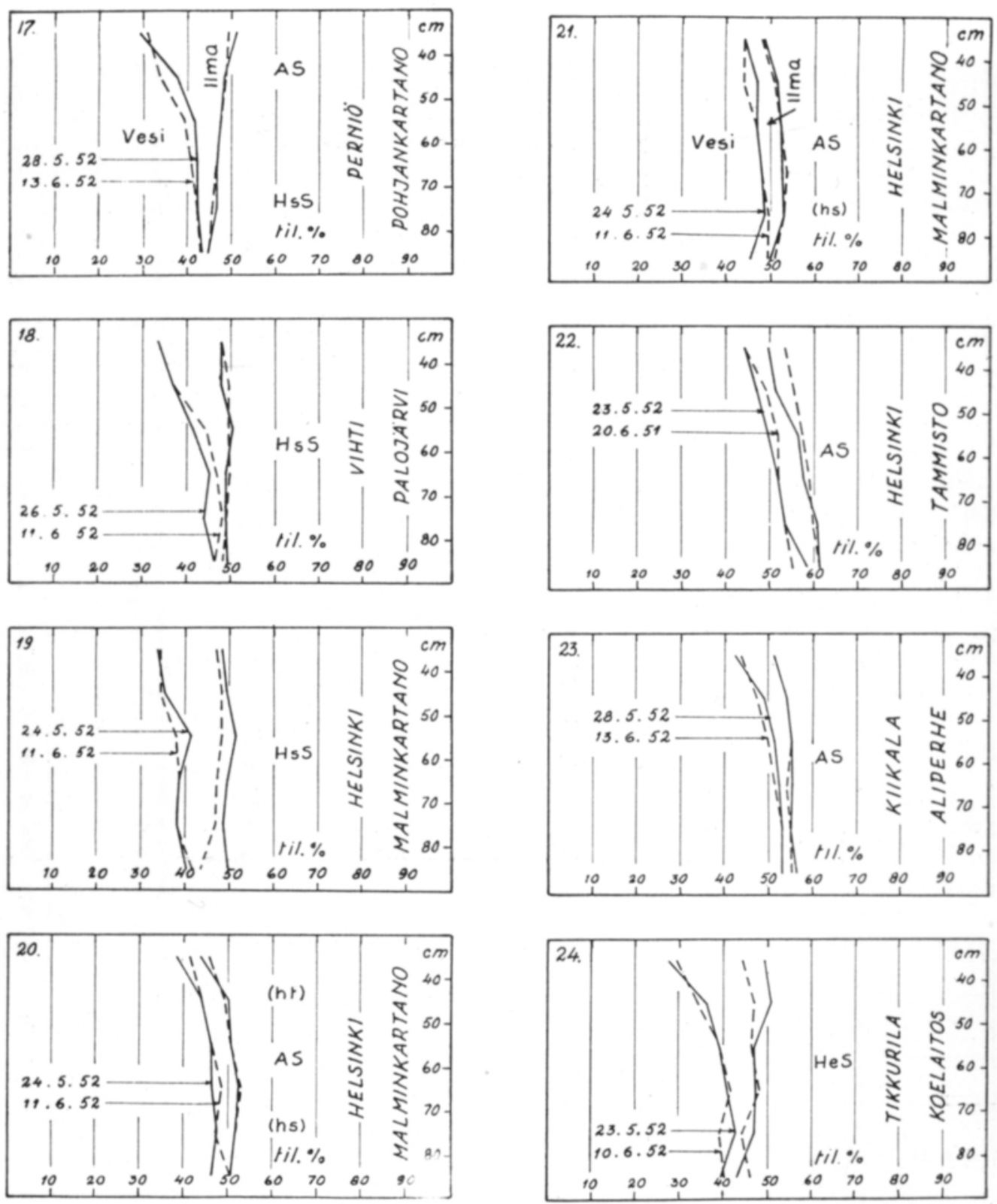

Piirrokset $17-24-$ Fig. 17-24. 

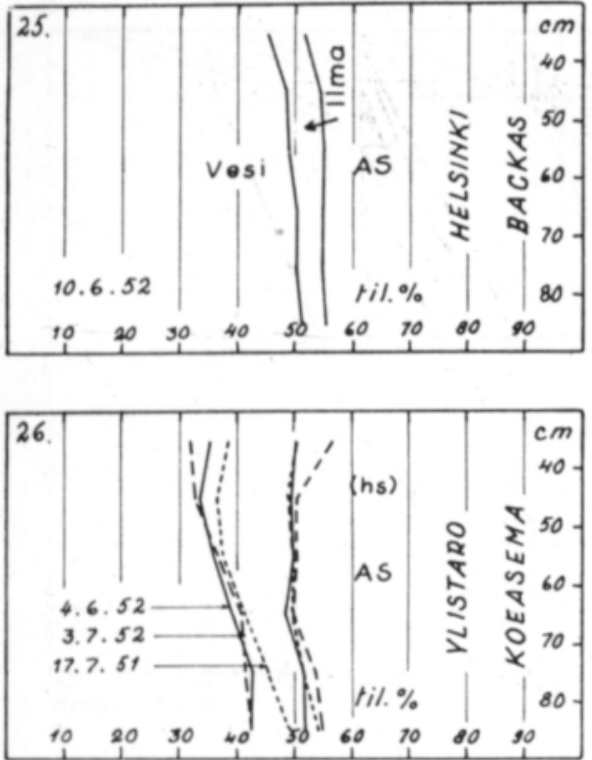
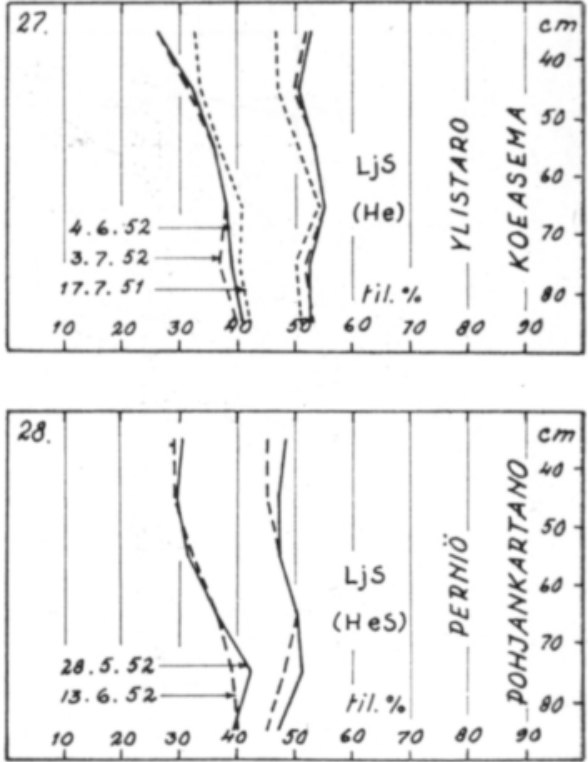

Piirrokset $25-28-$ Fig. 25-28.

N:o 8. Vihti. Samalla pellolla kuin koeala 5, mutta alempana loivassa rinteessä. Pohjakerros jokseenkin puhdasta kerrallista hienoa hietaa. $30-55 \mathrm{~cm}$ tyypillistä hiuemaata, hieman halkeillutta.

N:o 9. Sammatti. Loivan peltokummun laki. Selvästi kerrallista vaaleata hiuetta, syvemmällä hienoa hietaa.

N:o 10. Mustiala. Tasainen pelto, maalaji koko profilissa hiue. Punertava rautapodsolin B-taso ulottuu $55 \mathrm{~cm}: \mathrm{n}$ syvyyteen. Syvemmällä harmaata ja kerrallista.

N:o 11. Helsinki. Loivan kumpareen laki Tammiston pelloilla. Vaaleata kerrallista hiesua ja hiuetta. Kahtena keväänä ilmeni sama kenttäkapasiteettitila. Kesäkuusta elokuuhun 1951 vesipitoisuus on laskenut muutamalla prosentilla, mikä johtunee $\mathrm{mm}$. maan lämpiämisen aiheuttamasta valumisesta. Mahdollisesti puhtaaksi harattu 2 metrin läpimittainen koeala oli myös liian pieni estäăkseen ympäröivän viljakasvuston vedenoton vaikutuksen.

N:o 12. Laukaa. Loivan rinteen yläosa. Hyvin tyypillinen kerrallinen hiesu. Kokonaishuokostila pienin koko tutkimusaineistossa.

N:o 13. Laukaa. Loiva rinne, paksumultainen vanha pelto hiesumaalla. Madonreikiä ulottuu $50 \mathrm{~cm}: \mathrm{m}$ syvyyteen saakka. Syvemmällä savespitoisuus kasvaa ja kerrallisuus tulee selvemmäksi.

N:o 14-15. Karjalohja. Pieniä ja loivia peltokumpareita. Kyntökerros ohut ja vähämultainen, lasehtiva. Maata viljelty laajaperäisesti, etupäässä laitumena. Maalaji jankossa hiuesavi, syvemmällä hiesusavi. Jankon ilmatila on voimakkaan halkeilun vuoksi $50 \mathrm{~cm}: n$ syvyyteen saakka runsas, mutta siitä alaspäin yhtä pieni kuin kerrallisilla savimailla yleensäkin.

$\mathrm{N}$ :o 16. Noin $500 \mathrm{~m}$ edellisistä koealoista, maasto samantapainen, viljely vanhempi ja voimaperäisempi. Tyypillinen aitosavi muuttuu $60 \mathrm{~cm}: \mathrm{n}$ alapuolella tiiviiksi kerralliseksi hiesusaveksi, jossa ilmatila on hyvin pieni.

N:o 17. Perniö. Ylävä peltomaa. Tyypillistä etelä-Suomen rannikkoalueen hiedan ja hiesun sekaista aitosavea. Entisen maalajiluokituksen mukaan tällainen maa merkittiin »kevyeksi saveksi» (ks. 8).

N:o 18. Vihti. Aitosavea lähenevä hiesusavi alempana samalla pellolla kuin koealat 5 ja 8 . Jankossa melkoisesti halkeilua, joka loppuu $70 \mathrm{~cm}: \mathrm{n}$ syvyydessä.

N:o 19-21. Helsinki. Melko tasainen glasiaalisen savikerrostuman muodostama Malminkartanoon kuuluva peltoaukea. Tekstuuri vaihtelee hiesusavesta aitosaveen. Vain koealassa 19, joka on 


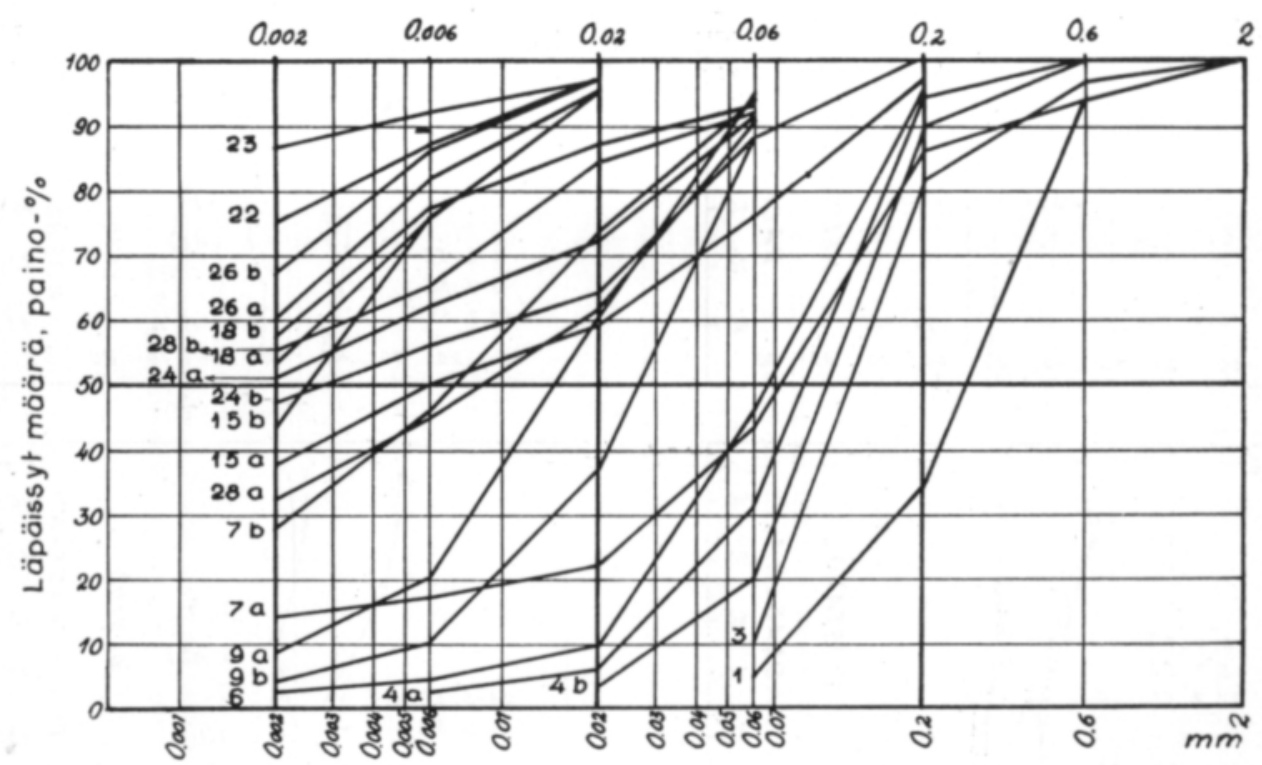

Piirros 29 - Fig. 29.

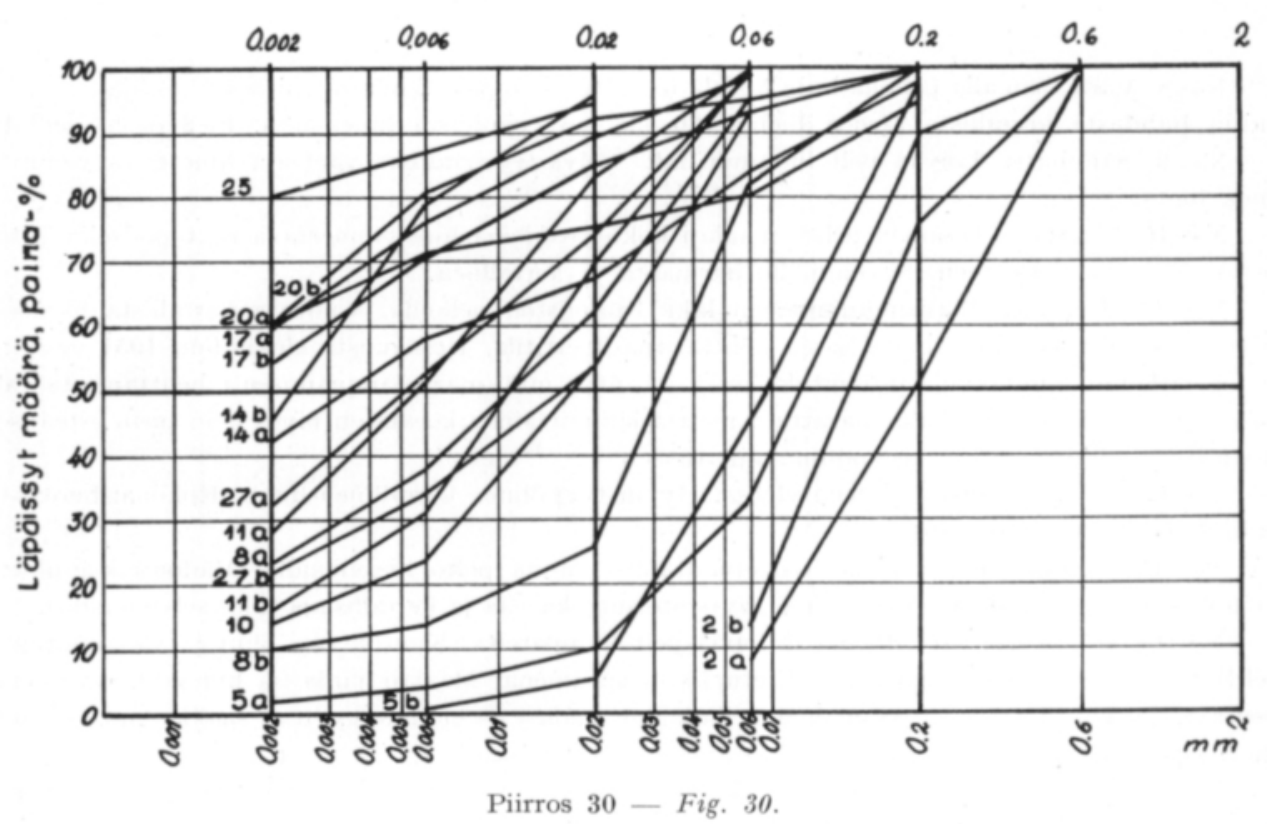

3 metrin päässä viemärin sortumasta, ilmeni selviä halkeamia $75 \mathrm{~cm}$ :n syvyyteen saakka. Sormin irroitellessa paljastui umpeen paisuneita srakoaiheita» myös koealassa 21.

N:o 22. Helsinki. Litorinakaudella uudelleen kerrostunut aitosavi Tammiston koekentällä (vrt. 7).

N:o 23. Kiikala. Tyypillinen ruskeansävyinen aitosavi laajan viljelysaukean keskellä. Profiilin yläosassa on etenkin vaakasuoria rakoja, jotka loppuvat n. $80 \mathrm{~cm}: \mathrm{n}$ syvyydessä.

N:o 24. Tikkurila. Keravanjokeen viettävä Maatalouskoelaitoksen pelto. Maa (lihava hiuesavi) on nähtävästi postglasiaalista tulvamuodostumaa, mutta pohjamaan humuspitoisuus on jokseenkin 


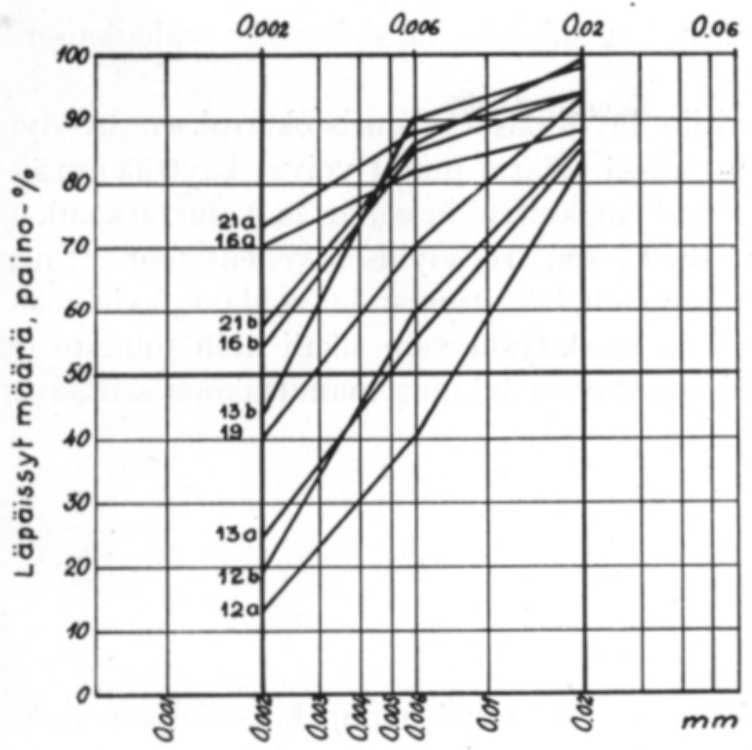

Piirros 31 - Fig. 31.
Piirrokset 29-31. Koealojen raekoostumus; $\mathrm{a}=40-50 \mathrm{~cm}, \mathrm{~b}=70-80 \mathrm{~cm}$, vain koealan numero $=$ molempien yllämainittujen kerrosten keskiarvo, kun niiden vălillä ei ole sanottavaa eroa.

Figures 29-31. Texture of the soils; $\dot{a}=$ $40-50 \mathrm{~cm}, b=70-80 \mathrm{~cm}$, number of the plot only $=$ the average of both above-mentioned layers when these are very similar.

yhtä alhainen kuin glasiaalisavissa, $0.9 \% 40-50 \mathrm{~cm}: \mathrm{n}$ syvyydessä. Maa on voimakkaasti halkeillut $50 \mathrm{~cm}: n$ syvyyteen saakka ja syvemmälläkin ilmenevät kiinnipaisuneet rakoaiheet helposti, kun maata irroitellaan. Hietakerros $77-80 \mathrm{~cm}$.

N:o 25. Helsinki. Backas. Yleisnäyte tasaisesta aitosavikentästä, jolla Juusela (5) on suorittanut laajoja salaojitukseen liittyviä tutkimuksia. Kasvien vedenkäytön takia Juuselan havainnoista ei kuitenkaan ilmene suoranainen kenttäkapasiteettitila.

N:o 26. Ylistaro. Ancylus-kautinen aitosavi tasaisella koekentällä. Ilmatila paljon suurempi kuin tutkituissa etelä-Suomen jäykissä glasiaalisavissa.

N:o 27. Liejusavi $50 \mathrm{~m}$ edellisestä koealasta. Maan tekstuuri vastaa hiuetta ja sen humuspitoisuus on $1-1.5 \%$. Voimakas permanentti halkeilu koko profiilissa.

N:o 28. Perniō. Tyypillinen mureneva ruostelaikkuinen liejusavi eli urpasavi. Maan tekstuuri vastaa hiuesavea ja humuspitoisuus on $1.2-1.3 \%$.

\section{Tulosten tarkastelua}

Useimmissa koealoissa vesipitoisuus oli eri havaintoaikoina likimain sama, osoittaen siten selväpiirteistä kenttäkapasiteettitilaa (vrt. 3, p. 28). Tällöin maan ilmatila osoittaa mm. sen, kuinka paljon maahan voitaisiin varastoida pohjavettä kasvien tarpeiksi joko padotuksella tai esim. salaojitussyvyyttä madaltamalla. Karkeissa hietamaissa tämä tila on n. $20-30 \%$, mikä merkitsisi esim. 60 ja 120 $\mathrm{cm}: \mathrm{n}$ syvyystasojen välissä $\mathrm{n}$. $150 \mathrm{~mm}: \mathrm{n}$ kapasiteettia. Hienoissa hietamaissa ilmatila on n. $10 \%$ ja vastaava kapasiteetti $60 \mathrm{~mm}$. Samaa suuruusluokkaa ovat liejusavimaiden luvut. Varsinaisissa savimaissa syvempien kerrosten ilmatila on tavallisesti vain n. $2-5 \%$, joten niihin ei voi padotuksella varastoida enempää kuin $10-20 \mathrm{~mm}$ pohjavettä. Sensijaan ylemmän pohjamaakerroksen ilmatila on eräissä kevyehköissä savimaissa yllättävän suuri, jopa $20 \% 30-50 \mathrm{~cm}$ :n syvyydessä, 
millä saattaa olla suuri merkitys runsaiden sulamis- ja sadevesien väliaikaisena varastoimispaikkana.

Kenttäkapasiteettiluvuista voitaisiin myös laskea juuristokerroksen hyödyllinen vesikapasiteetti, jos tiedettäisiin, missä määrin juuret voivat käyttää hyväkseen pohjamaan vesivarastoa. Tämä voidaan kuitenkin selvittää vain pitkäaikaisilla kenttähavainnoilla eri kasveja viljeltäessä. "Hyödyllisen veden» teoreettinen (fysikaalisten voimien määräämä) alaraja eli lakastumisraja voidaan kyllä määrittää verrattain helposti, mutta sillä on merkitystä vain sikäli kuin juuristo on ao. kerroksessa riittävän tiheä. Suuntaa-antavina lukuina mainittakoon seuraavat pohjamaan lakastumisrajat (vrt. 3, 4):

$\begin{array}{lr}\text { karkea hieta } & 2 \text { til. \% } \\ \text { hieno hieta } & 10 \text { " " " } \\ \text { hiuesavi } & 20 " \text { " " } \\ \text { aitosavi } & 30 \text { " " }\end{array}$

JUUSELAN (5) julkaisemat tulokset ja eräät myöhemmin kipsiblokkimenetelmällä tekemämme havainnot viittaavat siihen, että heinäkasvit kuivana kesänä voivat käyttää hyväkseen jäykän saven pohjamaasta lähes kaiken hyödyllisen veden $\mathrm{n} .60-70 \mathrm{~cm}: \mathrm{n}$ syvyyteen saakka. Tämän tason alapuolella juuriston harvuus rajoittaa enenevässä määrin veden hyväksikäyttöä. JUUSELAN mittaustuloksista voidaan päätellä, että kasvit saivat $80-100 \mathrm{~cm}: n$ syvyydestä vielä $\mathrm{n}$. 10 til. \% vettä eli noin puolet teoreettisesta hyötykapasiteetista (vrt. 2).

Käsilläoleva tutkimus antaa myös lisävalaistusta kysymykseen, missä määrin maan huokoisuussuhteet riippuvat sen raekoostumuksesta. Näyttää siltä että karkeissa lajittuneissa maalajeissa aina hiukeeseen saakka humusvapaan pohjamaan kenttäkapasiteetti ja ilmatila määräytyvät pääasiassa raekoostumuksen mukaan. Ainakin nämä lajit olivat eri seuduilla olevissa koealoissa hyvin samanlaisia. Kaikille niille on myös yhteistä kokonaishuokostilan pieneneminen jankosta alaspäin. Tyypilliset aitosavet muodostavat mahdollisesti toisen ryhmän, jolla on tiettyjä tekstuurin määräämiä yhteisiä rakenneominaisuuksia, kuten pieni, $2-5 \%$ :n ilmatila ja kokonaishuokostilan suureneminen jankosta alaspäin. Yhteisten piirteiden edellytyksenä lienee samantapainen kuivatus- ja viljelyhistoria. Karkeusasteeltaan aitosaven ja hiukeen välissä olevien hiesu-, hiesusavi- ja hiuesavimaiden huokoisuussuhteet näyttävät vaihtelevan väljissä rajoissa riippumatta selvästi tekstuurista. Tutkitut kaksi liejusavea erottuvat selvästi omaksi ryhmäkseen, jossa pohjamaan ilmatila on suurempi kuin muissa savissa ja samaa suuruusluokkaa kuin hienoissa hietamaissa.

\section{KIRJALLISUUTTA}

(1) ANDersson, S. 1947. Om en ny jordborr. Grundförbättring 1: 230-237.

(2) $\rightarrow$ 1948. Markens vattenhushållning och torkan. Lantmannen (Stockholm) 1948, N:ot 24 ja 25. 
(3) Heinonen, R. 1954 a. Multakerroksen kosteussuhteista Suomen maalajeissa. Summary: Moisture conditions in Finnish topsoils. Agrogeol. julk. 62: 1-82.

(4) $\longrightarrow 1954 \mathrm{~b}$. Om den nyttiga vattencapaciteten i finska jordarter. Nord. jordbr.forskn. 36: $101-107$.

(5) Jưsel.A, T. 1945. Untersuchungen über den Einfluss des Entwässerungsverfahrens auf den Wassergehalt des Bodens, den Bodenfrost und die Bodentemperatur. Acta agr. fenn. 59: $1-212$.

(6) —— \& Wäre, M. 1956. Suomen peltojen kuivatustila. Draining condition of the cultivated fields in Finland. Maa- ja vesiteknillisiä tutkimuksia 8 : $1-89$.

(7) KrvineN, E. 1935. Uber die Ungleichmässigkeit des Ackerbodens. Agrogeol. julk. 37 : 1 -17.

(8) —— 1939. Savimaiden ominaisuuksista. Maanv.ins.yhd. vuosik. 1939: 83-105.

\title{
SUMMARY:
}

\section{POROSITY CONDITIONS IN FINNISH SUBSOILS}

\author{
Reijo Heinonen
}

\section{Department of Agricultural Chemistry, University of Helsinki}

The purpose of this study is to outline the total pore space, field capacity and air capacity relationships in the whole textural range of Finnish subsoils. The 28 test plots were chosen from different parts of southern Finland. The subsoil layer of $30-90 \mathrm{~cm}$. was sampled 1 to 3 times by means of a sampling tube (Photos 1-3). Each time four replicate cores were taken from the plot of one sq.yd. The land was kept clean so that the transpiration of the crop did not affect the results.

The sampling places and dates are entered in Figures 1 to 28 . The apparent soil volume is thereby divided into three parts, from left to right water (svesis), air (vilmas), and soil solids. The air capacity and total pore space were calculated after specific gravity determination in alcohol (method: Heinonen 1954 a, p. 77). The texture of the soils is given in Figures $29-31$. All of the soils, excluding nos. 27 and 28 , contain organic matter less than 1 per cent.

The moisture content is rather constant in most of the soils, indicating well defined field capacity. The results also indicate that in coarser soils ranging from medium sand to loam and, perhaps, in the heaviest glacial clays, too, the texture mainly determins the porosity relationships. A somewhat similar drainage and cropping history is obviously a necessary condition for the common profile characteristics in heavy clays. The porosity relationships of lighter clays are very variable. Nos. 27 and 28 are acid post-glacial clays ("muddy" or sgyttjas clay) with 1 to 1.5 per cent organic matter and very pronounced fragmental structure in the subsoil. 